\title{
Manganese-Schiff base complex immobilized silica materials for electrocatalytic oxygen reduction
}

\author{
VELLAICHAMY GANESAN*, MANAS PAL and MANOJ TIWARI \\ Department of Chemistry, Faculty of Science, Banaras Hindu University, Varanasi 221005 , India
}

MS received 20 April 2013; revised 25 May 2013

\begin{abstract}
Curtailment of platinum catalysts loading in fuel cell is a recent central issue. As substitutes, these days several organic metal chelate compounds having featured moieties of $M-N_{4}$ or $M-N_{2} O_{2}(M=$ transition metal ion) are being used as cathode catalysts in fuel cells. Here, in this study, we report in detail the electrocatalytic activity of manganese-Schiff base complexes for oxygen reduction reaction in $0.05 \mathrm{M} \mathrm{HClO}_{4}$ at room temperature. Actually, $[\mathrm{Mn}(\mathrm{salen})]^{+}: \quad\left[\mathrm{N}, \mathrm{N}^{\prime} \text {-bis(salicylaldehyde) ethylenediimino manganese(III) }\right]^{+}$and $\left[\mathrm{Mn}(\text { salophen) }]^{+}:\left[\mathbf{N}, \mathbf{N}^{\prime} \text {-bis(salicylaldehyde)-1,2-phenylenediimino manganese(III) }\right]^{+}\right.$were introduced into/onto the MCM-41 type silica spheres and used for the electrocatalytic reduction of oxygen. Synthesized materials were characterized by UV-Vis, FT-IR and electrochemical techniques. Significant low overpotential for oxygen reduction in $0.05 \mathrm{M} \mathrm{HClO}_{4}$ on $\left[\mathrm{Mn}(\text { salen) }]^{+}\right.$- and $\left[\mathrm{Mn}(\text { salophen) }]^{+}\right.$-incorporated silica-modified glassy carbon electrodes was observed.
\end{abstract}

Keywords. Oxygen reduction; electrocatalysis; MCM-41 type material.

\section{Introduction}

Oxygen reduction reaction (ORR) has received much attention for more than three decades because of its importance in fuel cells, metal-air batteries and $\mathrm{H}_{2} \mathrm{O}_{2}$ producing industries (Adzic et al 1998; Subhramannia et al 2008a, b; Liu et al 2010; Prakash et al 2010; Kundu et al 2011; Basu and Basu 2012; Lin et al 2013; Lu et al 2013). Since utilization of platinum as electrocatalyst increases cost of fuel cells, exploration for the development of cheap and cost-effective electrocatalysts such as metal oxides, metal alloys and transition metal macrocycles, upshots several chemically-modified electrodes with immobilized electrocatalyst for ORR (Adzic et al 1998). Similar to metal phthalocyanines and metal porphyrins (Ni and Anson 1985; Koc et al 2009; Pal and Ganesan 2009, 2012a, b) few Schiff base complexes are also (Ortiz and Park 2000; Pal and Ganesan 2012a, b) observed to offer encouraging electrocatalytic activity towards ORR. The most probable basis for such activity is supposed to be their conjugated structure with high chemical stability (Phougat and Vasudevan 1997; Pal and Ganesan 2012a, b). Based on these previous studies of free Schiff bases and its complexes, which are exhibiting biological (Soloshonok and Ono 1996), catalytic (Kureshy et al 1996), optical (Bhat et al 1996) and photochromic (Alarcon et al 1996) activities, [Mn(salen)] $]^{+}$and

\footnotetext{
*Author for correspondence (velganesh@yahoo.com; velgan@bhu.ac.in)
}

$[\mathrm{Mn}(\text { salophen })]^{+}$complexes ([N,N'-bis(salicylaldehyde) ethylenediimino manganese(III) $]^{+}$and $\left[N, N^{\prime}\right.$-bis(salicylaldehyde)-1,2 phenylenediimino manganese(III) $]^{+}$, respectively) have been chosen as the effective redox mediator for the present study. On the other hand, high surface area, uniform pore size, mechanical and thermal stability and lined-silanol groups confer the MCM-41 type mesoporous silica spheres (MSS) as potential host for variety of guest chemical species including metal nanoparticles and transition metal complexes (Pol et al 2002; Jiang et al 2005; Ganesan and Walcarius 2008; Pal and Ganesan 2009, 2010a, b, 2012a, b; Chen et al 2010). Therefore, immobilization of catalyst molecules on solid supports can be satisfactorily employed in the areas of catalysis (Caro et al 2002a, b; Pal and Ganesan 2009, $2010 \mathrm{a}, \mathrm{b})$. In this consequence, in the present work, we present the synthesis, characterization and electrocatalytic activities of $[\mathrm{Mn}(\text { salen })]^{+} /[\mathrm{Mn}(\text { salophen })]^{+}$incorporated mesoporous silica spheres, i.e. MSS-[Mn(salen) $]^{+}$ and MSS-[Mn(salophen) $]^{+}$towards the reduction of oxygen in acidic media.

\section{Experimental}

\subsection{Chemicals and reagents}

Tetraethoxysilane (TEOS, 98\%), was procured from Sigma-Aldrich, cetyltrimethylammonium bromide (CTAB) was from Himedia, polyvinyl alcohol, ammonia, ethylenediamine, salicylaldehyde and 1,2-phenylenediamine were 
obtained from SD Fine chemicals limited, India. Triple distilled water was used to prepare solutions all through the experiments and other reagents used in this study were of analytical grade.

\subsection{Synthetic procedures}

2.2a Synthesis of mesoporous silica spheres: For the synthesis of MCM-41 type mesoporous silica spheres (MSS), standard procedure is followed (Kresge et al 1992; Pal and Ganesan 2009, 2012a, b). Briefly, CTAB is dissolved in water-ethanol-ammonia mixture. TEOS in ethanol was then added to the surfactant and catalyst solution under vigorous stirring condition. The stirring was continued for $2 \mathrm{~h}$ at room temperature. The formed white precipitate was filtered on a Buchner funnel and washed with excess water and ethanol. The resulting powder was dried in vacuum for $24 \mathrm{~h}$. The CTAB was removed from the MSS material by acid/solvent extraction.

$2.2 \mathrm{~b}$ Synthesis of $[\mathrm{Mn}(\text { salen })]^{+}$and $[\mathrm{Mn}(\text { salophen })]^{+}$: Schiff base ligand $\left(\right.$ salenH$\left.H_{2}\right)$ was synthesized and purified according to a literature procedure (Bottcher et al 1993). In an Erlenmeyer flask (containing $100 \mathrm{~mL}$ of $95 \%$ ethanol) $10 \mathrm{~g}$ of salicylaldehyde was added. Then, the solution was heated to boil on a sand bath with constant stirring followed by addition of $2.8 \mathrm{~mL}$ of ethylenediamine. The stirring was continued for another $5 \mathrm{~min}$. Then, the flask was removed from sand bath and allowed to cool in room temperature and then in ice cold water. Yellowish crystals were collected on Buchner funnel, which was washed with ice cold ethanol and allowed to dry in air thoroughly. Similarly, salophen $\mathrm{H}_{2}$ was prepared according to literature (Chen et al 1995) by condensation of 1,2-phenylendiamine with salicylaldehyde $(1: 2 \mathrm{~mol}$ stoichiometric ratio in ethanol) at room temperature. The product was purified by recrystallization from ethanol. To prepare $[\mathrm{Mn}(\text { salen })]^{+}$(Kantam and Bharathi 1998), typically $3 \cdot 064 \mathrm{~g}$ of $\mathrm{Mn}(\mathrm{OAc})_{2} \cdot 4 \mathrm{H}_{2} \mathrm{O}$ was added to a solution of $1.34 \mathrm{~g}$ of salen $\mathrm{H}_{2}$ ligand in $25 \mathrm{~mL}$ of ethanol and dissolved. This solution was refluxed under air for $3 \mathrm{~h}$ at $80^{\circ} \mathrm{C}$ and cooled to room temperature. Then, $5 \mathrm{~mL}$ of saturated aqueous solution of sodium chloride was added to the reaction mixture and it was again refluxed for further $2 \mathrm{~h}$. The reaction mixture was then cooled again in an ice bath and the $[\mathrm{Mn}($ salen $)] \mathrm{Cl}$ was extracted with large amount of dichloromethane. The extractions were combined and evaporated to recover the product $[\mathrm{Mn}($ salen $)] \mathrm{Cl}$. $[\mathrm{Mn}($ salophen $)] \mathrm{Cl}$ was also prepared following the same procedure.

2.2c Incorporation of metal complexes into the MSS: Since the synthesized MSS contain long range channels with wide pore openings (Pal and Ganesan 2009), $[\mathrm{Mn}(\text { salen })]^{+}$and $[\mathrm{Mn}(\text { salophen })]^{+}$complexes can be easily incorporated into the channels. For incorporation, the below procedure is followed. $[\mathrm{Mn}(\text { salen })]^{+}$or $[\mathrm{Mn}$ (salophen) $]^{+}$was added to $0.5 \mathrm{~g}$ MSS in $25 \mathrm{~mL}$ of water in a $50 \mathrm{~mL}$ beaker. The solutions were equilibrated for about $24 \mathrm{~h}$ to incorporate maximum amount of the Schiff base complex on the channels of MSS. After $24 \mathrm{~h}$ of equilibration, the materials were filtered, washed with plenty of water and vacuum dried. The resulting materials are named as MSS-[Mn(salen) $]^{+}$and MSS-[Mn (salophen) $]^{+}$, respectively.

\subsection{Preparation of modified electrodes}

Aqueous colloidal solution (1\%) of the relevant materials (MSS-[Mn(salen)] $]^{+}$or MSS-[Mn(salophen)] $]^{+}$was prepared with $0.01 \%$ poly(vinyl alcohol) as a binder. Glassy carbon electrode (GC) surface was cleaned with alumina on a Buehler-felt pad, washed with water and methanol, sonicated for $5 \mathrm{~min}$ in water and air dried. Calculated amount $(5 \mu \mathrm{L})$ of the colloidal solution was dropped onto $0.07 \mathrm{~cm}^{2}$ of the dry GC and air-dried in the absence of light. These electrodes were used for the electrochemical studies within $24 \mathrm{~h}$.

\subsection{Instruments}

Fourier transform infrared (FT-IR) spectra of the solid samples were scanned in PerkinElmer FT-IR spectrometer (Spectrum Two, USA) using $\mathrm{KBr}$ pellets in the range of $400-4000 \mathrm{~cm}^{-1}$. SEM images were recorded from Quanta 200, FEI, Netherland operating at $20 \mathrm{kV}$. Electronic spectra of the metal complexes in solution and the corresponding metal complex incorporated silica materials (i.e. MSS-[Mn(salen) $]^{+}$and MSS-[Mn(salophen) $]^{+}$) were recorded using 2802 PC UNICO (USA) and UV 1700 Pharma Spec, Shimadzu UV-Vis absorption spectrophotometers, respectively. The powdered MSS-[Mn(salen) $]^{+}$ and MSS-[Mn(salophen) $]^{+}$materials were uniformly dispersed with Nujol mull and pasted on a filter paper strip to record the electronic spectra. Electrochemical experiments were performed on a $\mathrm{CH}$ instruments (CHI-660C, USA) electrochemical workstation. A three electrode one compartment cell setup with MSS- $[\mathrm{Mn}(\text { salen })]^{+}$or MSS$[\mathrm{Mn}(\text { salophen })]^{+}$modified GC as working electrode, $\mathrm{Pt}$ wire as counter electrode and $\mathrm{KCl}$ saturated calomel electrode (SCE) as reference electrode were used for electrochemical studies. All the electrochemical studies were performed at room temperature under nitrogen atmosphere unless otherwise indicated.

\section{Results and discussion}

\subsection{Characterization of materials}

UV-Vis absorption spectra, FT-IR, scanning electron microscopy (SEM) and cyclic voltammetric studies were 
employed to characterize the metal complexes, MSS, $\operatorname{MSS}-[\mathrm{Mn}(\text { salen })]^{+}$and MSS-[Mn(salophen) $]^{+}$materials.

3.1a $U V-V i s$ absorbance spectroscopy: Figure 1 depicts the UV-Vis absorbance spectra of MSS-[Mn(salen) $]^{+}$and MSS-[Mn(salophen) $]^{+}$materials and the corresponding solution absorbance spectra of the metal complexes in ethanol or acetonitrile. The UV-Vis spectrum of a $[\mathrm{Mn}(\text { salen })]^{+}$(figure 1a) and $\left[\mathrm{Mn}(\text { salophen) }]^{+}\right.$(figure 1b) shows typical metal $d \rightarrow d$ transition band around 410 and $446 \mathrm{~nm}$, respectively (Srinivasan et al 1986), which are present in their corresponding silica samples (i.e.

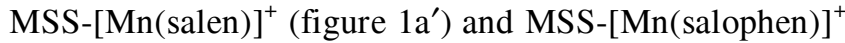
(figure $\left.1 b^{\prime}\right)$ ) also. These spectra clearly confirm the incorporation/adsorption of $[\mathrm{Mn}(\text { salen })]^{+}$and $[\mathrm{Mn}$ (salophen) $]^{+}$complexes within the MSS.

3.1b FT-IR Spectroscopy: Figure 2 shows FT-IR spectra of MSS, $[\mathrm{Mn}(\text { salen })]^{+}$and $[\mathrm{Mn}(\text { salophen })]^{+}$complexes, MSS-[Mn(salen) $]^{+}$and MSS-[Mn(salophen $\left.)\right]^{+}$ materials. Figure 2(a) shows the absence of any bands in the region of $1670-1300 \mathrm{~cm}^{-1}$ in the spectrum of MSS. The band appears at $3437 \mathrm{~cm}^{-1}$ is due to $\equiv \mathrm{SiOH} \cdots \mathrm{OSi} \equiv$ stretching vibrations of the free surface silanol groups of MSS. Two strong bands appear at 1085 and $800 \mathrm{~cm}^{-1}$, which could be assigned to asymmetric and symmetric stretching vibrations of $\mathrm{Si}-\mathrm{O}-\mathrm{Si}$ bridges, respectively. The band at $525 \mathrm{~cm}^{-1}$ corresponds to the $\mathrm{Si}-\mathrm{O}-\mathrm{Si}$ bending vibration of $\mathrm{SiO}_{2}$ tetrahedra. Spectra of free $[\mathrm{Mn}(\text { salen })]^{+}$ and $\left[\mathrm{Mn}(\text { salophen) }]^{+}\right.$complexes (figures 2(b) and (c), respectively) show bands due to $\mathrm{C}=\mathrm{C}-\mathrm{C}$ bond stretching of aromatic ring (between 1615 and $1450 \mathrm{~cm}^{-1}$ ), aromatic $\mathrm{C}-\mathrm{H}$ stretching (at $3110 \mathrm{~cm}^{-1}$ ), $\mathrm{C}-\mathrm{OH}$ bond (at $1194 \mathrm{~cm}^{-1}$ )

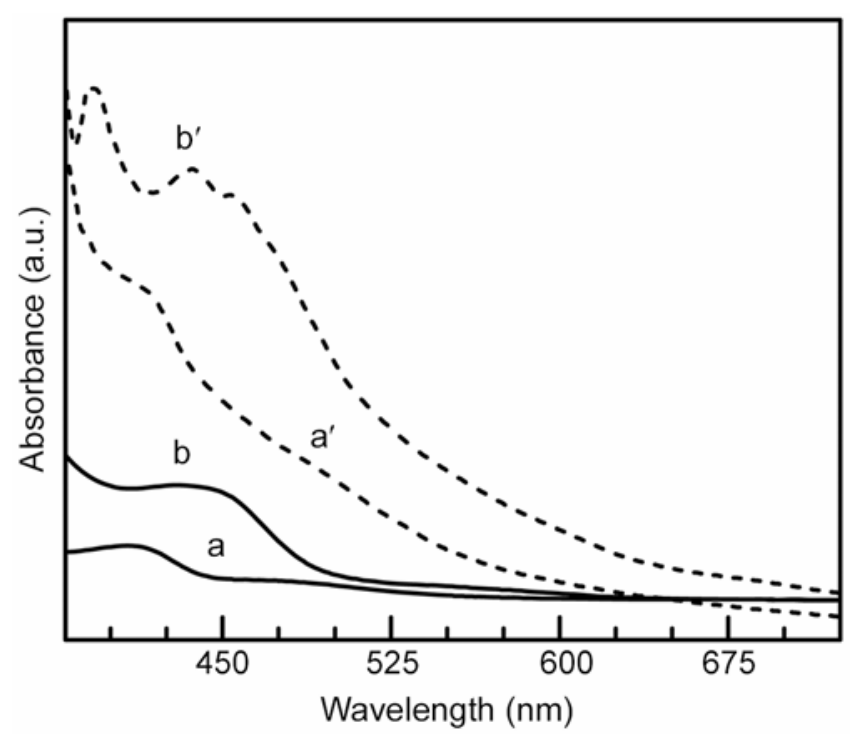

Figure 1. UV-Vis absorption spectra of: (a) $[\mathrm{Mn}(\text { salen })]^{+}$in ethanol, (b) $[\mathrm{Mn} \text { (salophen) }]^{+}$in acetonitrile and powdered MSS$[\mathrm{Mn}(\text { salen })]^{+}\left(\mathrm{a}^{\prime}\right)$ and MSS-[Mn(salophen $\left.)\right]^{+}\left(\mathrm{b}^{\prime}\right)$ materials. and $-\mathrm{C}=\mathrm{N}-$ bond (between 1690 and $1590 \mathrm{~cm}^{-1}$ ). The spectra of MSS-[Mn(salen) $]^{+}$(figure 2d) and MSS$\left[\mathrm{Mn}(\text { salophen }]^{+}\right.$(figure 2e) materials show the combined features of the corresponding metal complex and MSS with slight changes. All the vibration bands observed in the free metal complex is also observed in the corresponding MSS. However, the intensity of the bands is less (and some vibrations are so week to such an extent that the correct band position can not be measured) probably due to the low amount of the incorporated/ adsorbed metal complex. As there are meager changes in the vibrational band positions, it is concluded that the structure of the metal complexes are not altered on incorporation into MSS and the interaction between the metal complex and MSS is weak.

3.1c SEM analysis: SEM images of the MSS-based samples are shown in figure 3(A-C). Figure 3(A) clearly depicts uniform distribution of the material and presence of uniform-sized MSS spheres. Similarly, SEM images of MSS- $[\mathrm{Mn}(\text { salen })]^{+}$and MSS- $[\mathrm{Mn}(\text { salophen })]^{+}$materials are shown in figures $3(\mathrm{~B})$ and $(\mathrm{C})$ respectively, where distinct difference in the morphology of the materials (than the MSS (figure 3A)) can be seen due to the adsorption/incorporation of metal complexes. The channels and porosity present in the MSS is clearly visible in the SEM image of magnified scale (figure 3D) and the spheres are separated. However, due to the adsorption/incorporation of $[\mathrm{Mn}(\text { salen })]^{+}$and $[\mathrm{Mn}(\text { salophen })]^{+}$onto/into the channels of MSS, the porosity is not clearly visible in MSS$[\mathrm{Mn}(\text { salen })]^{+}$and MSS-[Mn(salophen) $]^{+}$materials (figures $3(\mathrm{E})$ and $(\mathrm{F})$, respectively) and the spheres are aggregated to some extent.

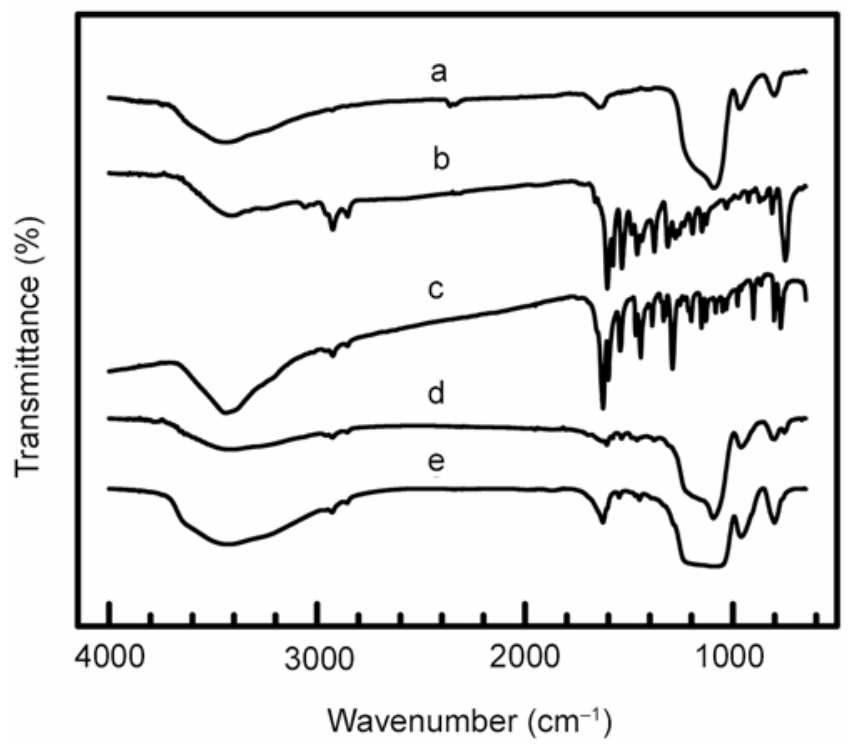

Figure 2. FT-IR spectra of (a) MSS, (b) $\left[\mathrm{Mn}(\text { salen) }]^{+}\right.$, (c) $[\mathrm{Mn}(\text { salophen })]^{+}, \quad$ (d) MSS-[Mn(salen) $]^{+}$and (e) MSS$[\mathrm{Mn}(\text { salophen })]^{+}$materials. 

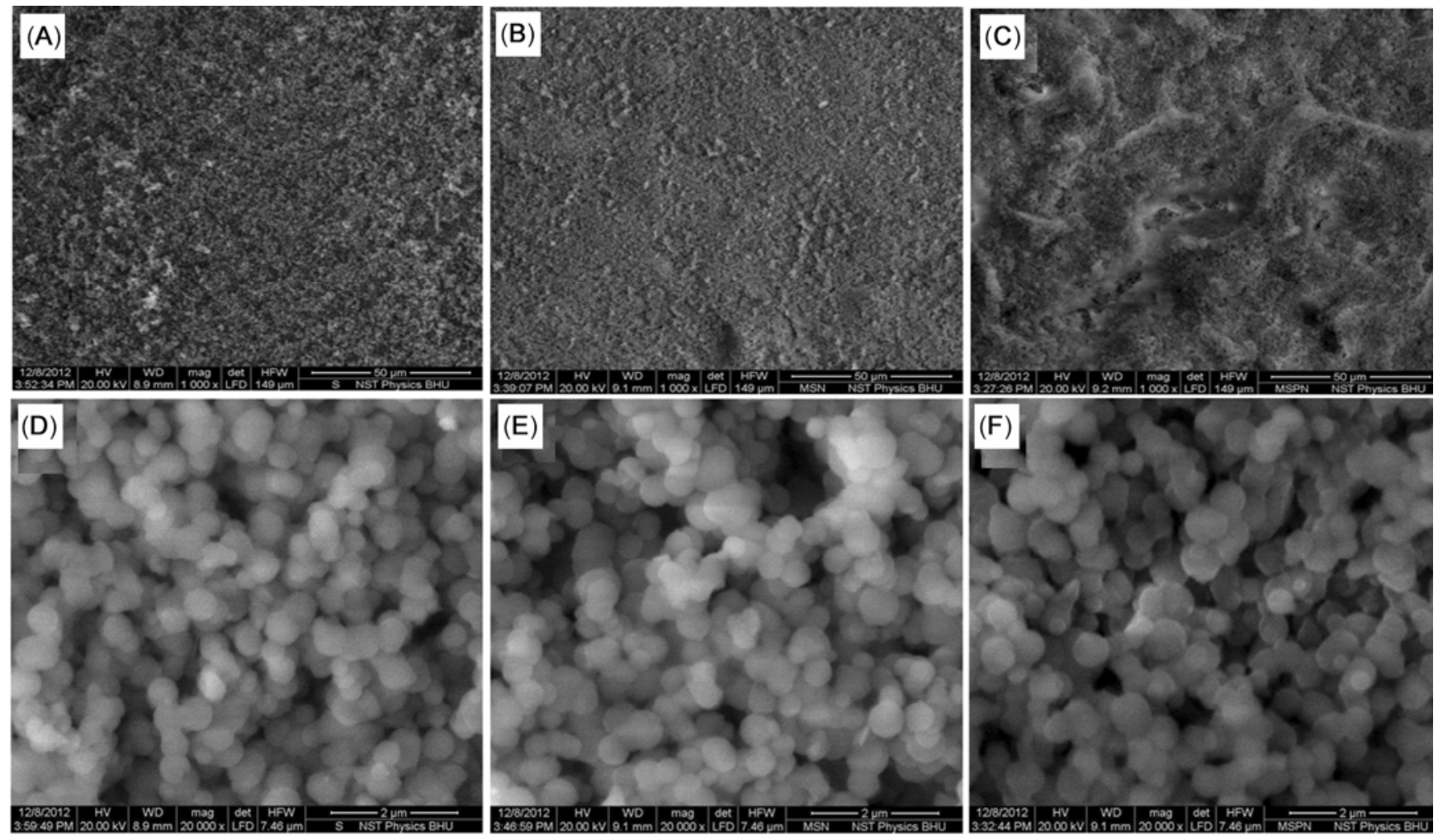

Figure 3. SEM images of MSS (A and D), MSS-[Mn(salen) $]^{+}(\mathbf{B}$ and $\mathbf{E})$ and MSS-[Mn(salophen $\left.)\right]^{+}(\mathbf{C}$ and $\mathbf{F})$ materials.
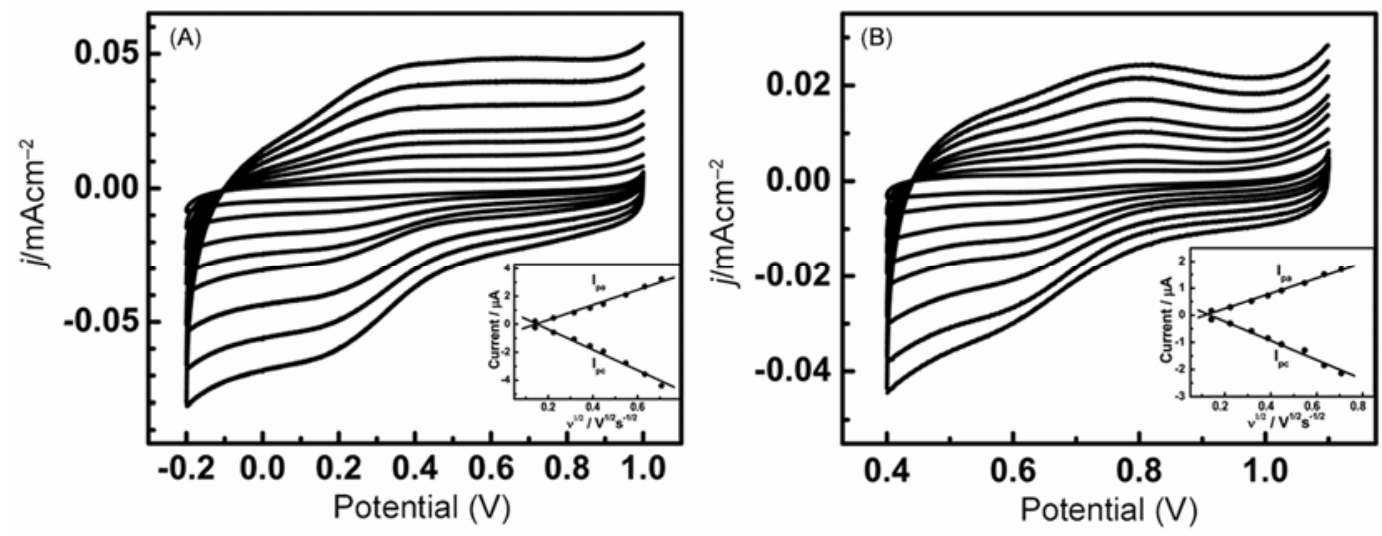

Figure 4. Current density-voltage characteristics of (A) GC/MSS-[Mn(salen) $]^{+}$and (B) GC/MSS$[\mathrm{Mn}(\text { salophen })]^{+}$in $0.05 \mathrm{M} \mathrm{HClO}_{4}$ with different scan rates. Insets: Plots of $I_{\mathrm{pa}}$ and $I_{\mathrm{pc}}$ against square root of scan rate.

3.1d Electrochemical study: Potentiodynamic response of GC electrode modified with $\mathrm{MSS}-[\mathrm{Mn}(\mathrm{salen})]^{+}$and MSS-[Mn(salophen) $]^{+}$materials in $0.05 \mathrm{M} \mathrm{HClO}_{4}$ solution at different scan rate is shown in figure 4 . It is observed that current density-voltage characteristics do not change with different scan rates. Insets of figure 4 show the plot of $I_{\mathrm{pa}}$ and $I_{\mathrm{pc}}$ vs square root of scan rate, which is linear revealing that the redox processes are diffusioncontrolled. Cyclic voltammogram $(\mathrm{CV})$ of $[\mathrm{Mn}(\text { salen })]^{+}$ reveals a quasi-reversible one electron redox reaction $\left(E_{\mathrm{pa}}=0.42 \mathrm{~V}, E_{\mathrm{pc}}=0.25 \mathrm{~V}\right)$ which corresponds to $\left[\mathrm{Mn}^{\mathrm{III}}\right.$ (salen) $]^{+} /\left[\mathrm{Mn}^{\mathrm{II}}\right.$ (salen)] redox couple $\left(E_{1 / 2}=0 \cdot 34 \mathrm{~V}\right)$. Whereas, in case of $[\mathrm{Mn}(\text { salophen })]^{+}$, the $\mathrm{CV}$ shows a quasi-reversible one electron transfer $\left(E_{\mathrm{pa}}=0.81 \mathrm{~V}\right.$, $\left.E_{\mathrm{pc}}=0.62 \mathrm{~V}\right)$, which corresponds to $\left[\mathrm{Mn}^{\mathrm{III}} \text { (salophen) }\right]^{+}$ $\left[\mathrm{Mn}^{\mathrm{II}}\right.$ (salophen)] redox couple $\left(E_{1 / 2}=0.72 \mathrm{~V}\right)$.

\subsection{Electrocatalytic oxygen reduction}

In figure 5(A), curves (a) and (b) represent the current density-voltage characteristics of GC/MSS (blank electrode) 

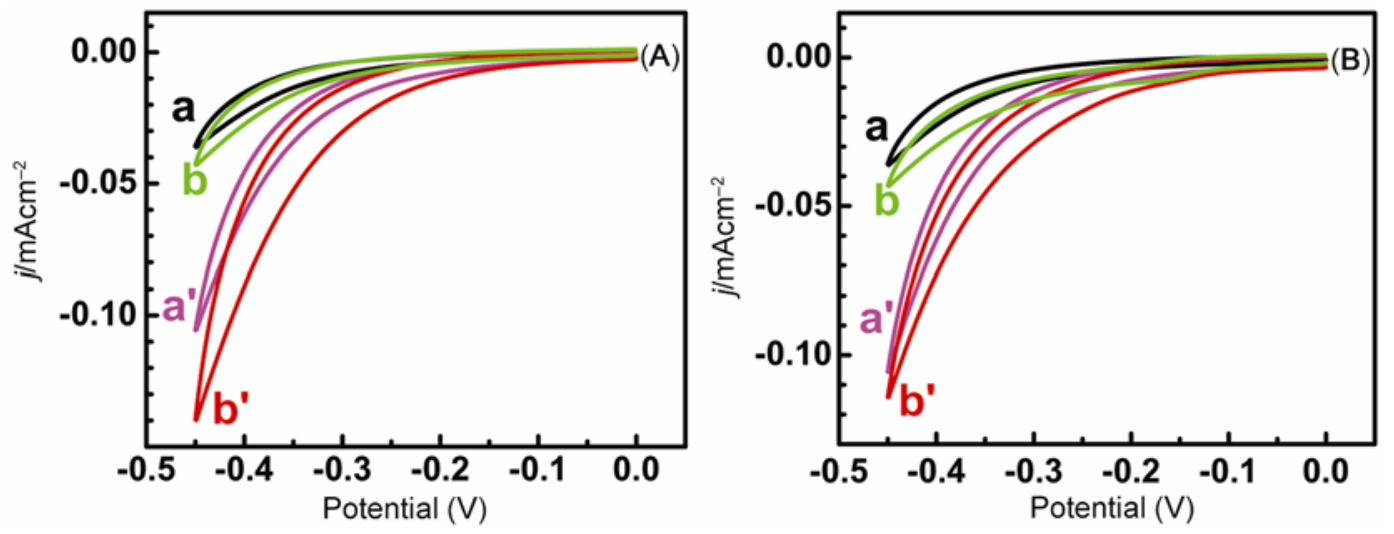

Figure 5. Current density-voltage characteristics of (A) GC/MSS (a, $\left.\mathrm{a}^{\prime}\right)$ and GC/MSS-[Mn(salen)] ${ }^{+}$ $\left(b, b^{\prime}\right)$ and (B) GC/MSS (a, $\left.a^{\prime}\right)$ and GC/MSS-[Mn(salophen) $]^{+}\left(b, b^{\prime}\right)$ in $0.05 \mathrm{M} \mathrm{HClO}_{4}$ in the absence of $(a, b)$ and presence $\left(a^{\prime}, b^{\prime}\right)$ of oxygen.

and GC/MSS-[Mn(salen) $]^{+}$electrodes, respectively, in $\mathrm{N}_{2}$ saturated aqueous acidic solution. Curves $\left(\mathrm{a}^{\prime}\right)$ and $\left(\mathrm{b}^{\prime}\right)$ represent the current density-voltage characteristics of the same electrodes in oxygen saturated solution, respectively. The solution is saturated with either $\mathrm{N}_{2}$ or $\mathrm{O}_{2}$ by purging the respective gas through the solution for about 15-20 min. High current density is observed for the reduction of oxygen at GC/MSS-[Mn(salen) $]^{+}$with a decrease in the onset of the oxygen reduction potential compared to the blank electrode. Figure 5(B) shows the current density-voltage characteristics of GC/MSS and GC/MSS-[Mn(salophen) $]^{+}$electrodes in the presence and absence of oxygen. Even though the increase in current density at GC/MSS-[Mn(salophen) $]^{+}$electrode is not very much, when compared with blank electrode, a considerable decrease in the onset of the oxygen reduction potential is observed. Hence, it can be concluded that both $\mathrm{GC} /$ MSS-[Mn(salen) $]^{+}$and GC/MSS-[Mn(salophen) $]^{+}$electrodes electrocatalytically reduces oxygen.

Chronoamperometry is carried out to calculate the catalytic rate constant, $k_{\mathrm{c}}$. This can be calculated based on the relation given below in (1) (Bard and Faulkner 1980).

$$
I_{\mathrm{c}} / I_{\mathrm{l}}=\pi^{1 / 2}\left(k_{\mathrm{c}} C_{\mathrm{b}} t\right)^{1 / 2},
$$

where $I_{\mathrm{c}}$ represents the obtained current in presence of oxygen and $I_{1}$ represents the same in the absence of oxygen. $C_{\mathrm{b}}$ denotes the bulk concentration of oxygen in solution $\left(1.2 \times 10^{-6} \mathrm{M}\right.$, Chen et al 2009) and $t$ represents the time. The values of $k_{\mathrm{c}}$ obtained for GC/MSS-[Mn(salen)] and GC/MSS-[Mn(salophen) $]^{+}$electrodes are $3.7 \times 10^{5}$ and $2.65 \times 10^{5} \mathrm{M}^{-1} \mathrm{~s}^{-1}$ respectively. These values are higher than the previously reported $k_{\mathrm{c}}$ values which utilize metal complex consisting electrode modifiers under similar experimental conditions (Pal and Ganesan 2009, 2012a, b).

\section{Conclusions}

$[\mathrm{Mn}(\mathrm{salen})]^{+}$and $[\mathrm{Mn} \text { (salophen) }]^{+}$complexes have been prepared, characterized and incorporated/adsorbed on
MCM-41 type silica material. These new materials electrocatalytically reduces oxygen efficiently. Based on the reduction current and catalytic rate constant, MSS-[Mn (salophen) $]^{+}$material shows better catalytic activity to reduce oxygen electrochemically compared to MSS$[\mathrm{Mn}(\text { salen })]^{+}$.

\section{Acknowledgements}

Financial support from CSIR and DST is gratefully acknowledged. We acknowledge Prof O N Srivastava, Department of Physics, Banaras Hindu University for SEM facilities.

\section{References}

Adzic R R 1998 In Electrocatalysis (eds) J Lipkowski and P N Ross (New York: Wiley-VCH) p. 197

Alarcon S H, Olivieri A C, Nordon A and Harris R K 1996 J. Chem. Soc. Perkin Trans. 22293

Bard A J and Faulkner L R 1980 Electrochemical methods: fundamentals and applications (New York: Wiley)

Basu D and Basu S 2012 Int. J. Hydrogen Energy 374678

Bhat K, Chang K J, Aggarwal M D, Wang W S, Penn B G and Frazier D O 1996 Mater. Chem. Phys. 44261

Bottcher A, Elian H, Jager E G, Langfelderova H, Mazur M, Muller L, Paulus H, Pelikan P, Rudolph M and Valko M 1993 Inorg. Chem. 324131

Caro C A, Bedioui F and Zagal J H 2002 Electrochim. Acta 47 1489

Chen H, Cronin J A and Archer R D 1995 Inorg. Chem. 34 2306

Chen R, Li H, Chu D and Wang G 2009 J. Phys. Chem. C 113 20689

Chen Z, Cui Z M, Niu F, Jiang L and Song W G 2010 Chem. Commun. 466524

Ganesan V and Walcarius A 2008 Mater. Sci. Eng. B149 123

Jiang Z J, Liu C Y and Sun L W 2005 J. Phys. Chem. B109 1730

Kantam M L and Bharathi B 1998 Catal. Lett. 55235 
Koc I, Camur M, Bulut M and Ozkaya A R 2009 Catal. Lett. 131370

Kresge C T, Leonowicz M E, Roth W J, Vartuli J C and Beck J S 1992 Nature 359710

Kundu M, Mahanty S and Basu R N 2011 Mater. Lett. 651105 Kureshy R I, Khan N H, Abdi S H R and Bhatt A K 1996 J. Mol. Catal. A: Chem. 11033

Lin Z, Waller G H, Liu Yan, Liu Meilin and Wong C P 2013 Nano Energy 241

Liu R, Wu D, Feng X and Mullen K 2010 Angew. Chem. Int. Ed. 492565

Lu Z J, Bao S J, Gou Y T, Cai C J, Ji C C, Xu M W, Song J and Wang R 2013 RSC Adv. 33990

Ni C L and Anson F C 1985 Inorg. Chem. 244754

Ortiz B and Park S M 2000 Bull. Korean Chem. Soc. 21405

Pal M and Ganesan V 2009 Langmuir 2513264
Pal M and Ganesan V 2010a Analyst 1352711

Pal M and Ganesan V 2010b Electrochim. Acta 554071

Pal M and Ganesan V 2012a J. Electroanal. Chem. 6727

Pal M and Ganesan V 2012b Catal. Sci. Technol. 22383

Phougat N and Vasudevan P 1997 J. Power Sources 69161

Pol V G, Srivastava D N, Palchik O, Palchik V, Slifkin M A, Weiss A M and Gedanken A 2002 Langmuir 183352

Prakash A S, Manikandan P, Ramesha K, Sathiya M, Tarascon J M and Shukla A K 2010 Chem. Mater. 222857

Soloshonok V A and Ono T 1996 Tetrahedron 5214701

Srinivasan K, Michaud P and Kochi J K 1986 J. Am. Chem. Soc. 1082309

Subhramannia M, Kannan R, Komath I, Aslam M and Pillai V K 2008 Chem. Mater. 20601

Subhramannia M, Kannan R and Pillai V K 2008 Langmuir 24 3576 